\title{
Magnetocardiography-Guided Management of an Unusual Case of Isoimmune Complete Atrioventricular Block Complicated by Ventricular Tachycardia
}

\author{
Bibhuti Das $^{a}$ Bettina F. Cuneo ${ }^{b}$ Mark Ovadia ${ }^{b} \quad$ Janette F. Strasburger ${ }^{c}$ \\ Christopher Johnsrude ${ }^{a}$ Ronald T. Wakai ${ }^{d}$

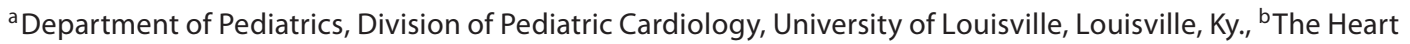 \\ Institute of Children, University of Illinois at Chicago School of Medicine, Chicago, III., 'Department of Pediatrics, \\ Division of Pediatric Cardiology, Medical College of Wisconsin, Milwaukee, Wisc., and ${ }^{\mathrm{d}}$ Department of Medical \\ Physics, University of Wisconsin Madison, Madison, Wisc., USA
}

\section{Key Words}

Arrhythmia $\cdot$ AV block • Magnetocardiography

\begin{abstract}
A fetus who was diagnosed at 25 weeks of gestation with isoimmune AV block presented at 34 weeks with a precipitous fall in ventricular rate and periods of tachycardia. Magnetocardiography revealed the tachycardia to be ventricular. After delivery, nonsustained ventricular tachycardia continued. The baby then successfully paced, and at higher ventricular rates the tachycardia resolved. Five years later the child has normal ventricular function and is doing well.
\end{abstract}

Copyright $\odot 2008$ S. Karger AG, Basel

The technique of fetal magnetocardiography (fMCG) has elucidated important features of fetal arrhythmias and has become an important tool in guiding in utero management of these fetuses [1-5]. Complete atrioventricular (AV) block is the most common finding in affected fetuses exposed to maternal SSA/Ro and SSB/La ribonuclear proteins (isoimmune AV block) [6], but other cardiac manifestations of immune-mediated damage include transient incomplete AV block [7], junctional ectopic tachycardia [8], endocardial fibroelastosis $[9,10]$, and cardiomyopathy $[11,12]$. However, even in large series of isoimmune $\mathrm{AV}$ block, ventricular tachycardia (VT) is rarely diagnosed [13]. Whether this is because VT is not a common manifestation of disease, or VT has been incorrectly diagnosed by M-Mode/Doppler technology, is not known. We had the opportunity to use fMCG to diagnose VT in a fetus with isoimmune AV block, and followed this infant after delivery.

\section{Case Report}

Bradycardia was detected in a female fetus during a routine obstetric ultrasound performed on a 36-year-old G8P5A2 mother at 25 weeks gestation. The mother had symptoms of joint pain and unexplained rash, but did not have diagnosis of a specific connective tissue disease. The fetal echocardiogram performed several

This research was supported by NIH grants R01HL63174 (R.T.W.) and R21H0049022 (J.F.S.).

\section{KARGER}

(C) 2008 S. Karger AG, Base

Fax +41613061234

E-Mail karger@karger.ch

www.karger.com www.karger.com/fdt
Bettina Cuneo, MD

The Heart Institute for Children, Hope Children's Hospital

4440 W. 95 th Street

Oak Lawn, IL 60645 (USA)

Tel. +1 708684 580, Fax +1 708648 4068, E Mail cuneo@thic.com 

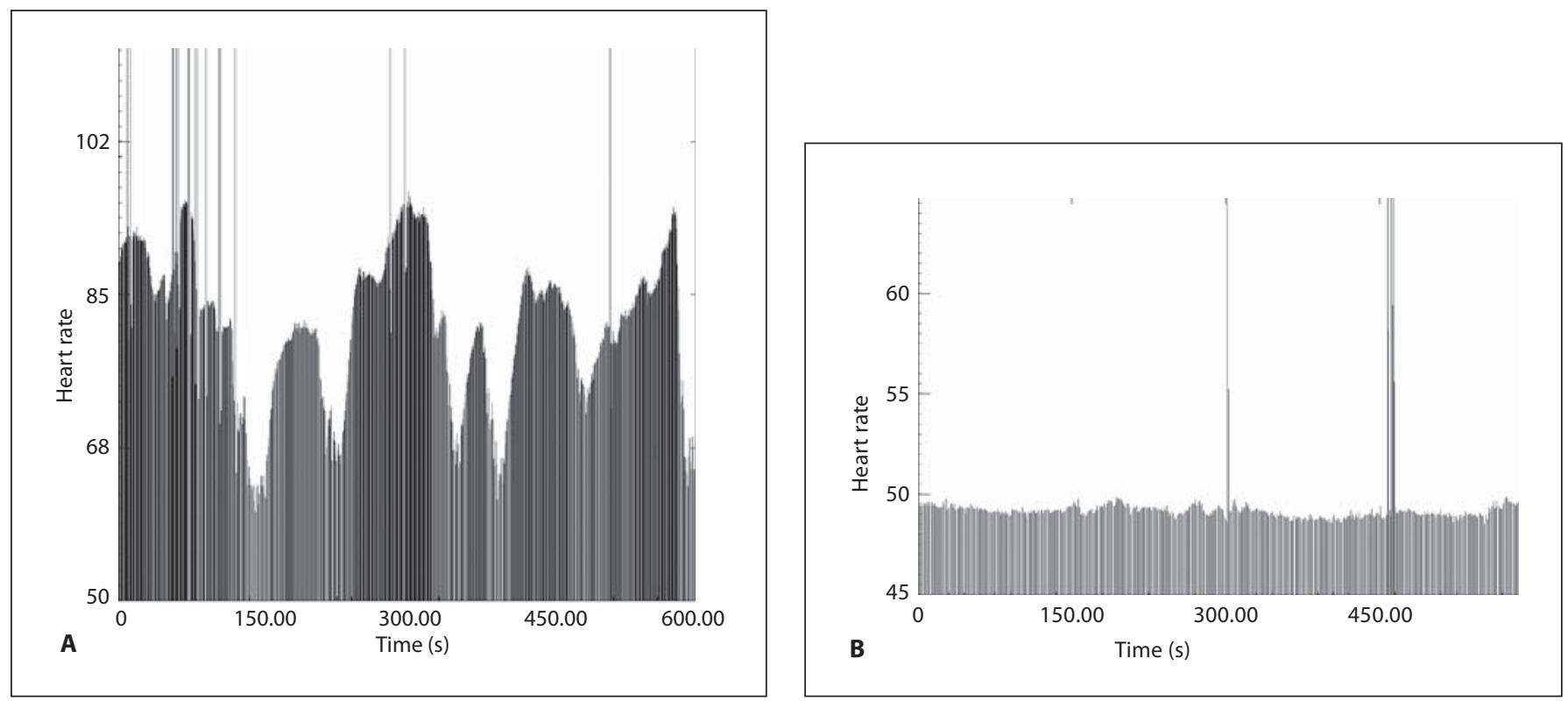

Fig. 1. Fetal heart rate patterns of acceleration. Each individual black line is an R-R interval. The graph shows the heart rate over $5 \mathrm{~min}$. A At 28 weeks, the tracing shows good variability over a wide ventricular rate range. B At 34 weeks, not only has the ventricular rate dropped precipitously, but there is no variability whatsoever in the ventricular rate range. The tall lines represent ventricular ectopy.

Table 1. Magnetocardiography results at 28 and 34 weeks in a fetus with isoimmune complete AV block

\begin{tabular}{lllllll}
\hline $\begin{array}{l}\text { GA } \\
\text { weeks }\end{array}$ & $\begin{array}{l}\text { Atrial rate, bpm } \\
\text { mean (range) }\end{array}$ & $\begin{array}{l}\text { Ventricular rate, bpm } \\
\text { mean (range) }\end{array}$ & $\begin{array}{l}\text { Reactive } \\
\text { HR pattern }\end{array}$ & $\begin{array}{l}\text { ectopy } \\
\%\end{array}$ & $\begin{array}{l}\text { VT } \\
\%\end{array}$ & $\begin{array}{l}\text { QTc } \\
\text { ms }\end{array}$ \\
\hline 28 & $130(120-155)$ & $63(60-96)$ & yes & 6.7 & none & 484 \\
34 & $130(118-160)$ & $50(49-59)$ & no & 3.1 & 0.1 & 574 \\
\hline
\end{tabular}

hours after the ultrasound revealed third-degree AV block with a ventricular rate of 63 and an atrial rate of $120 \mathrm{bpm}$. The fetal heart was structurally normal with good biventricular systolic function and no signs of heart failure or endocardial fibroelastosis. The mother was immediately started on Dexamethasone $4 \mathrm{mg}$ orally once a day.

At 28 weeks, an fMCG was performed in the Department of Medical Physics at the University of Wisconsin in Madison using a 37-channel biomagnetometer in a specially constructed low-permeability room, as previously described [2]. Atrial and ventricular rates, QRS duration and QT and PR intervals were measured from the signal-averaged fMCG. 5-10 tracings each of 10-15 min duration were recorded from multiple probe positions, then digitized and band-pass filtered $(1-80 \mathrm{~Hz})$. Fetal heart rate accelerations were correlated with fetal movement by simultaneous actocardiography. This initial fMCG showed a reactive heart rate pattern (fig. 1A) and no other arrhythmia (table 1).

Weekly sonograms from 26-33 weeks gestation showed no change in the heart rate or cardiac function. At 34 weeks, the fetal ventricular rate dropped to $48 \mathrm{bpm}$. A second $\mathrm{fMCG}$ showed a non-reactive heart rate pattern (fig. 1B) and several episodes of $\mathrm{VT}$ at rates of $85-180 \mathrm{bpm}$ (fig. 2, table 1). Because of the findings of VT and the poor heart rate variability, the infant was delivered that same day by cesarean section. The postnatal 12-lead electrocardiogram recorded at $2 \mathrm{~h}$ of age revealed a ventricular rate of 45 $\mathrm{bpm}$, an atrial rate of $150 \mathrm{bpm}$ and third-degree AV block (QTc of $442 \mathrm{~ms}$ ). During continuous monitoring in the nursery, episodes of non-sustained VT were noted. Isoproterenol failed to increase the ventricular rate $>50 \mathrm{bpm}$, so a temporary transvenous pacing catheter was placed. Despite an increased heart rate, over the next several hours the infant developed hypotension and decreased urine output. Adrenal insufficiency was suspected and later confirmed by low serum cortisol levels. The infant stabilized after solumedrol infusion. On day 10 , an epicardial dual chamber pacemaker was implanted. The baby was discharged home in good condition on day 17. She was treated with hydrocortisone for 2 months. Five years later, the child is healthy, with normal ventricular function. Based on numerous ambulatory ECGs, VT has not recurred. 
Fig. 2. Fetal magnetocardiograph at 34 weeks gestation from 3 of the 37 channels. The lower channel displays the maternal QRS (arrows). Note that the QRS complexes of ventricular origin are distinct from intrinsic narrow QRS complexes of the fetus' escape rhythm. The ventricular arrhythmia appears to be nearly monomorphic, suggesting a single focus. These QRS complexes are not likely to reflect aberrancy of intermittent AV conducted beats because the ventricular rate is faster than the atrial rate. Between episodes of ventricular arrhythmia, AV dissociation can be appreciated with apparent resetting of the intrinsic ventricular escape rhythm. Bottom tracing is maternal in origin.

Fig. 3. Postnatal 12-lead electrocardiogram in the newborn with congenital complete AV block and ventricular arrhythmias documented by fMCG. Baseline artifact is seen. Atrial rate is $166 \mathrm{bpm}$, ventricular rate is $45 \mathrm{bpm}$, QT interval is $485 \mathrm{~ms}$, and QTc is $442 \mathrm{~ms}$.
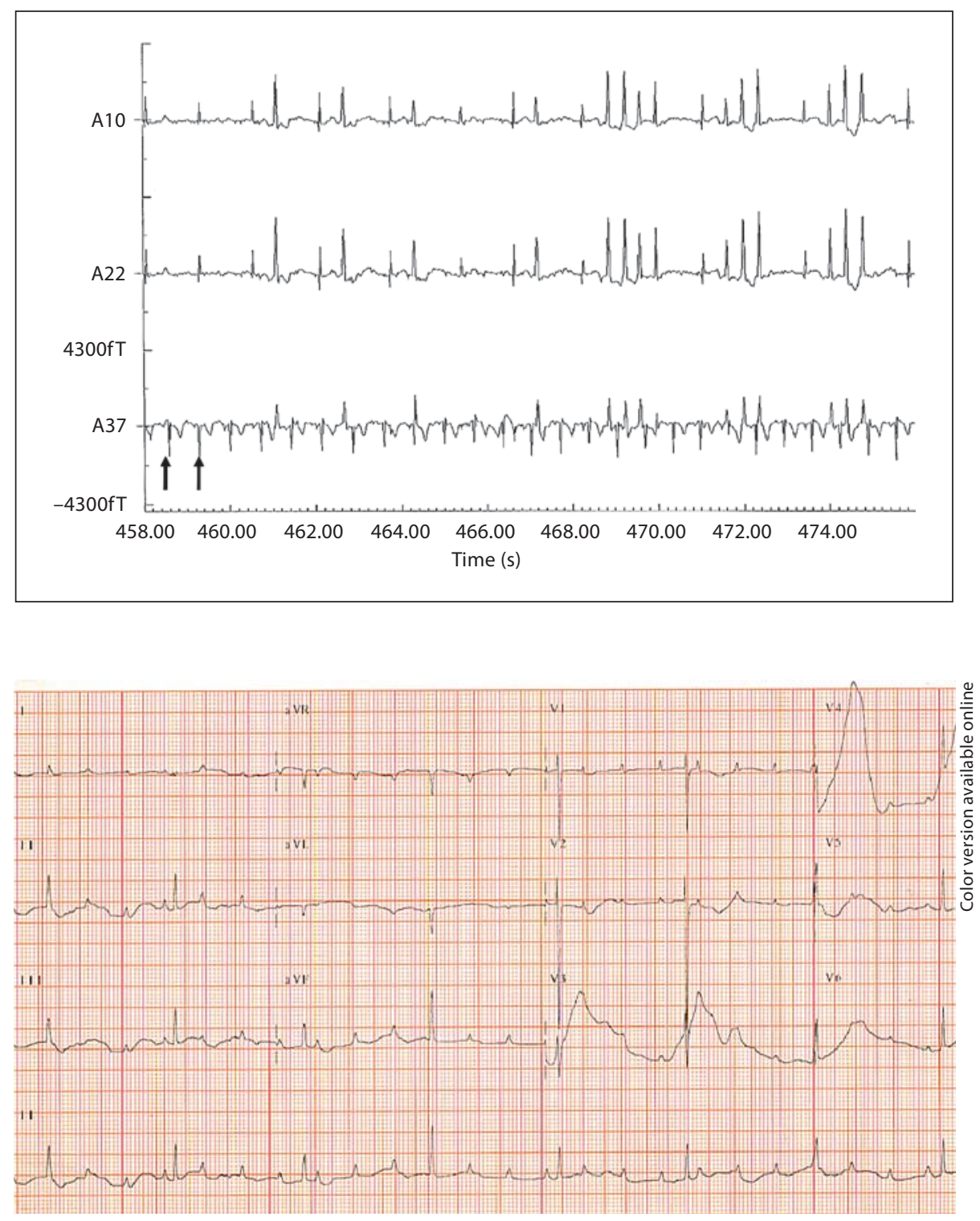

\section{Discussion}

We report the unusual occurrence of isoimmune complete AV block and VT diagnosed by fMCG after a dramatic decrease in the ventricular rate in a 34 week fetus. Other unusual features are that the occurrence late in gestation after previous fMCG showed only third-degree AV block and that the VT occurred 9 weeks after the initiation of transplacental anti-inflammatory treatment. These findings led to an immediate operative delivery of a non-hydropic infant who was paced shortly thereafter and has survived with normal ventricular function.
The most common technique for the diagnosis of fetal arrhythmias evaluates the AV relationship and atrial and ventricular rates by M-Mode or Doppler echocardiography. However, echocardiography measures the mechanical effect of an electrical event rather than direct recordings of cardiac electrical impulses. In addition, diagnosis is difficult if the arrhythmia is transient and since measurements of conduction intervals are necessary for diagnosis (such as long QT syndrome or bundle branch block). Recently, the use of tissue velocity imaging, which allows precise timing of atrial and ventricular events, has increased the sophistication of echocardiography arrhythmia diagnosis [14], but conduction intervals other than 
the P-R interval can only be measured by fMCG or fetal electrocardiography.

Fetal electrocardiogram, which has the potential to be more easily available and less expensive than fMCG, remains limited in arrhythmia diagnosis because the maternal electrocardiogram voltage potential is $10-100$ times stronger than the fetal signal resulting in significant artifact. Additionally, useful signals from the fetus are difficult to obtain after 27 weeks, probably due to insulating properties of vernix caseosa [15]. Such problems are not encountered with $\mathrm{AMCG}$, which reliably measures signals from 20-40 weeks of gestation, provided that the recordings are made within a magnetically shielded room.

In the fetus reported here, it is unknown why the ventricular rate dropped abruptly in only 1 week's time. It may be that despite the anti-inflammatory treatment there was on-going damage to the conduction system, resulting in a slower ventricular pacemaker more distal from the AV node. The finding that the QRS duration was narrow at this lower rate suggests that the new ventricular focus was proximal to the bundle of His.

The occurrence of VT accompanying isoimmune AV block in the fetus is unusual. VT may be an escape rhythm due to the low ventricular rate, or it may be due to myocardial ischemia secondary to low cardiac output from the abrupt fall in heart rate. Both may further be affected by progressive autoantibody-mediated myocardial injury. We further speculate that the findings of VT with severe bradycardia may be one of the mechanisms of sudden death in the fetus with isoimmune disease. These findings underscore the importance of vigilant monitoring in the third trimester of fetuses with isoimmune disease and no heart failure, even if they seem clinically stable.

\section{References}

1 Wakai RT, Leuthold AC, Cripe L, Martin CB: Assessment of fetal rhythm in complete congenital heart block by magnetocardiography. PACE 2000;23:1047-1050.

-2 Wakai TR, Leuthold AC, Martin CB: Atrial and ventricular fetal heart rate patterns in isolated congenital complete heart block detected by magnetocardiography. Am J Obstet Gynecol 1998;179:258-260.

-3 Mendez T, Achenbach S, Beinder E, Hofbeck M, Klinghammer L, Singer H, Moshage W, Daniel WG: Usefulness of magnetocardiography for the investigation of fetal arrhythmias. Am J Cardiol 2001;88:334-836.

-4 Wakai RT, Strasburger JF, Li Z, Deal BJ, Gotteiner NL: Magnetocardiographic rhythm patterns at initiation and termination of fetal supraventricular tachycardia. Circulation 2003;107:307-312.

5 Cuneo BF, Ovadia M, Strasburger JF, et al: Prenatal diagnosis and in utero treatment of torsades de pointes associated with congenital long QT syndrome. Am J Cardiol 2003;91: 1395-1398.
Costedoat-Chalumeau N, Georgin-Lavialle S, Amoura Z, Piette JC: Anti-SSA/Ro and anti-SSB/La antibody-mediated congenital heart block. Lupus 2005;14:660-664.

7 Cuneo BF, Strasburger JF, Wakai RT, Ovadia $\mathrm{M}$ : Conduction system disease in fetuses evaluated for irregular cardiac rhythm. Fetal Diagn Ther 2006;21:307-313.

-8 Dubin AM, Cuneo BF, Strasburger JF, Wakai RT, Van Hare GF, Rosenthal DN: Congenital junctional ectopic tachycardia and congenital complete atrioventricular block: a shared etiology? Heart Rhythm 2005;2:313-315.

-9 Jaeggi ET, Hamilton RM, Silverman ED, Zamora SA, Hornberger LK: Outcome of children with fetal, neonatal or childhood diagnosis of isolated congenital atrioventricular block. J Am Coll Cardiol 2002;39:130 137.

10 Nield LE, Silverman ED, Taylor GP, et al: Maternal anti-Ro and anti-La antibody-associated endocardial fibroelastosis. Circulation 2002;105:843-848.
11 Udink ten Cate FE, Breur JM, Cohen MI, et al: Dilated cardiomyopathy in isolated congenital complete atrioventricular block: early and long-term risk in children. J Am Coll Cardiol 2001;37:1129-1134.

12 Lida M, Inamura N, Takeuchi M: Newborn infant with maternal anti-SSA antibody-induced complete heart block accompanying cardiomyopathy. Circulation J 2006;70:147149.

13 Zhao H, Cuneo B, Strasburger J, et al: Electrophysiological characteristics of fetal AV block. JACC 2008;91:77-84

14 Rein AJJT, O'Donnell C, Geva T, et al: Use of tissue velocity imaging in the diagnosis of fetal cardiac arrhythmias. Circulation 2002; 106:1827-1833.

15 Stinstra JG, Peters MJ: The influence of fetoabdominal tissues on fetal ECGs and MCGs. Arch Physiol Biochem 2002;110:165176. 